\title{
Tyrosyl phosphorylation toggles a Runx1 switch
}

\author{
Benjamin G. Neel ${ }^{1,2}$ and Nancy A. Speck ${ }^{3,4}$ \\ ${ }^{1}$ Campbell Family Cancer Research Institute, Ontario Cancer Institute, Princess Margaret Hospital, University Health Network, \\ Toronto, Ontario M5G 1L7, Canada; ${ }^{2}$ Department of Medical Biophysics, University of Toronto, Toronto, Ontario M5G 2M9, \\ Canada; ${ }^{3}$ Abramson Family Cancer Research Institute, Department of Cell and Developmental Biology, Perelman School \\ of Medicine, University of Pennsylvania, Philadelphia, Pennsylvania 19104, USA
}

The Runx1 transcription factor is post-translationally modified by seryl/threonyl phosphorylation, acetylation, and methylation that control its interactions with transcription factor partners and epigenetic coregulators. In this issue of Genes \& Development, Huang and colleagues (pp. 1587-1601) describe how the regulation of Runx1 tyrosyl phosphorylation by Src family kinases and the Shp2 phosphatase toggle Runx1's interactions between different coregulatory molecules.

The connection between signaling and the gene expression circuitry often contains a transcription factor "switch" that is regulated by phosphorylation. This can be an on-off switch in which a transcription factor subunit is inactive or sequestered in one state, and phosphorylation or dephosphorylation activates it. Mechanisms by which a change in phosphorylation status activates a transcription factor complex can include translocation of one of its components to the nucleus, protection from proteolytic degradation, increased DNA-binding affinity, or association with/disassociation from transcription factor partners or coregulatory molecules. Classic examples of onoff switches are the signal transducers and activators of transcription (STAT) proteins, which are phosphorylated by the Janus-activated kinases (JAKs). Unphosphorylated, inactive STAT usually resides in the cytoplasm and is unable to bind DNA. Upon phosphorylation by JAKs, the STATs homodimerize or heterodimerize, translocate into the nucleus, bind DNA, and activate gene expression. The JAK/STAT pathway is unusual in that it is activated by tyrosyl phosphorylation, whereas the great majority of transcription factor switches toggled by phosphorylation use seryl/threonyl phosphorylation. In this issue of Genes \& Development, Huang et al. (2012) describe a new transcription factor switch driven by tyrosyl phosphorylation, consisting of a DNA-binding subunit of the heterodimeric

[Keywords: RUNX1; tyrosine phosphorylation; c-Src; Shp2; megakaryocyte; T cell]

${ }^{4}$ Corresponding author

E-mail nancyas@exchange.upenn.edu

Article is online at http://www.genesdev.org/cgi/doi/10.1101/gad.198051.112. core-binding factors (Runx1), Src family kinases (SFKs), and the protein tyrosine phosphatase Shp2.

Runxl is a sequence-specific DNA-binding transcription factor involved in multiple developmental processes in mammals, including hematopoiesis, neurogenesis, hair follicle development, and chondrogenesis. In hematopoiesis, Runx1 is essential for the formation of hematopoietic stem cells (HSCs) from endothelium during embryonic development (North et al. 1999), although it is no longer critically required in HSCs once they form, and its deletion only minimally impacts functional HSC numbers (Ichikawa et al. 2004; Growney et al. 2005; Cai et al. 2011). Runxl is essential, though, for the terminal differentiation of several blood cell lineages, including T cells, B cells, invariant natural killer cells (V $\alpha 14 \mathrm{i} N K T)$, basophils, and megakaryocytes (Ichikawa et al. 2004; Growney et al. 2005; Djuretic et al. 2009; Mukai et al. 2012). Runx 1 is required in multiple T-cell developmental stages. The initial steps of T-cell differentiation in the thymus involve progression through a series of four $\mathrm{CD}^{-}$ CD8- ("double-negative") T-cell precursor stages (DN1$\mathrm{DN} 4)$, followed by a $\mathrm{CD} 4^{+} \mathrm{CD} 8^{+}$"double-positive" stage. $\mathrm{T}$ cells then choose to become either $\mathrm{CD} 4^{+}$(helper T cells) or $\mathrm{CD}^{+}$(cytotoxic $\mathrm{T}$ cells). Runx1 is required for two steps within the double-negative progression, from DN2 to DN3 and from DN3 to DN4 (Ichikawa et al. 2004; Growney et al. 2005; Egawa et al. 2007). As discussed below, Runx1 is also involved in differentiation of the $\mathrm{CD} 8^{+} \mathrm{T}$-cell lineage and has major roles in the elaboration of helper T-cell subsets in the periphery, particularly Th17 and regulatory $\mathrm{T}$ cells. The transcriptional networks in which Runxl participates in T-cell development are complex, and we refer interested readers to more comprehensive reviews of this topic by other investigators (Collins et al. 2009; Diuretic et al. 2009; Wong et al. 2011).

Deletion of Runx1 in the fetal liver or adult bone marrow also severely impairs megakaryocyte differentiation (Ichikawa et al. 2004; Growney et al. 2005). In the absence of Runx1, circulating platelet numbers are reduced, megakaryocyte progenitor numbers increase, and large, polyploid megakaryocytes are replaced by lower-ploidy micromegakaryocytes in the bone marrow. Autosomal dominant mutations in RUNX1 cause familial platelet 
disorder (FPD) with propensity to acute myeloid leukemia (AML), in which patients present with thrombocytopenia and/or functional platelet abnormalities and have a $35 \%$ lifetime incidence of AML, a striking demonstration of the importance of RUNX1 dosage in maintaining normal hematopoiesis and suppressing leukemia (Song et al. 1999).

Many somatically acquired mutations in RUNX1 are found in various hematological malignancies, including de novo and therapy-related AML, myelodysplastic syndrome (MDS), chronic myelomonocytic leukemia (CMML), and acute lymphocytic leukemia (both pre-B-ALL and T-ALL) (Zelent et al. 2004; Grossmann et al. 2011a; Mangan and Speck 2011; Zhang et al. 2012). Mutations include chromosomal rearrangements and loss-of-function (amorphic), neomorphic, and anti-morphic mutations. RUNX1 mutations in chronic myelogenous leukemia (CML) are seen in the context of conversion of the chronic phase to blast crisis (Grossmann et al. 2011b). RUNX1 mutations are categorized as "class II" mutations that primarily serve to impair hematopoietic differentiation.

Runx 1 is both an activator and repressor of transcription and can toggle between these modes of action in various developmental contexts and on different target genes. Runx 1 also has distinct effects on gene regulation as cells differentiate down a particular pathway. For example, Runxl regulates transcription of the Cd4 gene differently at successive stages of T-cell development. Runx1 protein is present in $\mathrm{CD}^{-} \mathrm{CD}^{-}$(double-negative) $\mathrm{T}$ cells, $\mathrm{CD}^{+} \mathrm{CD}^{+}$(double-positive) $\mathrm{T}$ cells, and $\mathrm{CD} 4^{+}$ and $\mathrm{CD} 8^{+} \mathrm{T}$ cells (Lorsbach et al. 2004). Runxl actively silences $C d 4$ in $\mathrm{CD}^{-}{ }^{-} \mathrm{CD} 8^{-}$cells (Taniuchi et al. 2002) but no longer represses $C d 4$ expression in double-positive cells. Moreover, when double-positive cells choose to differentiate down the CD8 pathway, Runx1, in collaboration with its sibling, Runx3, again silences $C d 4$ expression in $\mathrm{CD}^{+}$cells (with Runx3 playing the major role) (Taniuchi et al. 2002; Woolf et al. 2003).

Whether Runxl activates or represses gene expression is mediated by interactions with different coregulatory proteins. This phenomenon was first documented in Drosophila, in which the Runx1 homolog Lozenge was shown to activate transcription of D-Pax2 in cone cells in collaboration with the Notch and epidermal growth factor nuclear effectors Suppressor of Hairless and Pnpt2, while in the same cells, Lozenge partners with Cut to repress deadpan expression (Flores et al. 2000; Canon and Banerjee 2003). Runx1 interacts with multiple transcription factors in hematopoietic cells. Partners in T cells include Ets1, MYB, T-bet, ROR $\gamma$ t, and FoxP3 (Gu et al. 2000; Hernandez-Munain and Krangel 2002; Djuretic et al. 2009; Wong et al. 2011), and partners in megakaryocytes include Fli1 and Gata1 (Elagib et al. 2003; Huang et al. 2009). Runx1 also interacts with more broadly expressed epigenetic coregulators such as transducin-like enhancer of split (TLE), histone acetyltransferases (p300/ CBP, MOZ, and MORF), histone methyltransferases (PRMT1, MLL, SUV39H1, and Polycomb group proteins), histone deacetylase complexes (mSin3a and HDAC1,3), and chromatin remodeling complexes (SWI/SNF) (Levanon et al. 1998; Yoshida and Kitabayashi 2008; Wang et al. 2009; Bakshi et al. 2010; Guo and Friedman 2011; Huang et al. 2011; Yu et al. 2012). Previous studies have shown that interactions with these epigenetic regulators are modulated by post-translational modifications of Runxl, which include seryl/threonyl phosphorylation, methylation, and acetylation (Wang et al. 2009). Now, Huang et al. (2012) add tyrosyl phosphorylation to this list.

Previously, these investigators identified Runx1-interacting proteins by biotin-tagging Runx 1 and purifying it with its associated proteins from a megakaryocytic precursor cell line by streptavidin affinity chromatography (Huang et al. 2009). They discovered some of the usual suspects on the list of associated proteins-transcription factors, epigenetic coregulators, and cyclin-dependent kinases (CDK)-but in addition, they identified the nonreceptor tyrosine kinase c-Src and the tyrosine phosphatase Shp2 (Ptpn11). Although there have been numerous reports of seryl/threonyl phosphorylation of Runx1 by several different kinases, including $c \mathrm{dk} 1 /$ cyclin $\mathrm{B}$ and cdk6/cyclin D3, Erk, and the homeodomain-interacting protein kinases (Hipk1/Hipk2), (Tanaka et al. 1996; Aikawa et al. 2006; Biggs et al. 2006; L Zhang et al. 2008; Guo and Friedman 2011), the inclusion of c-Src and Shp2 on the list of Runx1-binding partners suggested that it might also be tyrosyl phosphorylated. The investigators confirmed this supposition by performing phosphotyrosine immunoblotting and then mapped the tyrosyl phosphorylation sites on Runxl by a combination of mass spectrometry and mutational analysis. They also observed Runx1 tyrosyl phosphorylation in another megakaryocyte cell line and in murine thymocytes.

The phoshorylated tyrosine residues lie in two of the less well-characterized regions of Runx1, both of which function to dampen Runxl activity (Fig. 1). One region was shown in biochemical studies to inhibit DNA binding. Purified full-length Runxl assumes an autoinhibited conformation that causes it to bind naked DNA relatively poorly in vitro, with an affinity $\sim 70$-fold lower than that of the isolated DNA-binding Runt domain (Gu et al. 2000). The inhibitory activity is conferred by sequences C-terminal to the DNA-binding Runt domain and can be counteracted by association with Runxl's non-DNA-binding partner, $\mathrm{CBF} \beta$, or by a cooperating transcription factor, Ets1 (Gu et al. 2000). Although the boundaries of this inhibitory region are not well defined (Gu et al. 2000), it includes sequences between the DNA-binding Runt domain and the transcriptional activation domain (AD) that contain three of the newly identified tyrosyl phosphorylation sites. The other sites map to a transcriptional inhibitory domain (ID) that had been identified using Runx1-responsive reporter genes in cell-based assays (Kanno et al. 1998). These two inhibitory regions flank the $\mathrm{AD}$, which binds the histone acetyltransferase p300 (Kitabayashi et al. 1998). Notably, both inhibitory regions also contain sites of seryl/threonyl phosphorylation, particularly the sequences $\mathrm{N}$-terminal to the AD (Fig. 1). The location of most phosphorylated residues to regions of the Runx 1 protein known to contain inhibitory regions that modulate DNA binding or 
Neel and Speck

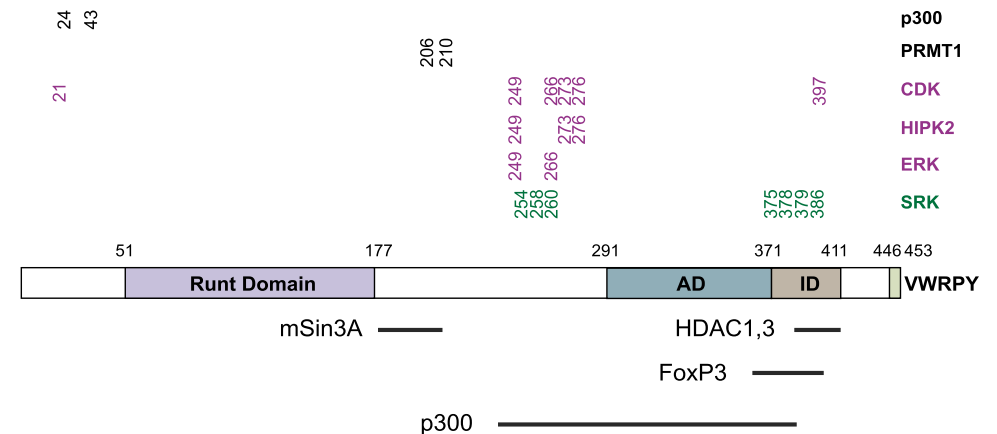

Figure 1. Schematic diagram of Runx1 with sites of post-translational modifications mapped. In green text are the tyrosyl phosphorylation sites, purple shows seryl/threonyl phosphorylation sites, and black indicates the methylation (PRMT1) and acetylation (p300) sites. Runt domain is the DNA- and CBF $\beta$-binding domain. VWRPY is the C-terminal pentapeptide required for binding TLE. Shown below are mapped interaction sites for several coregulatory proteins. transactivation suggests that a complex interplay between seryl/threonyl and tyrosyl phosphorylation might be critical to the precise regulation of Runxl activity during development.

Huang et al. (2012) showed that Runxl tyrosyl phosphorylation is dynamically regulated, as phosphorylation decreased dramatically during 12-O-tetradecanoylphorbol-13-acetate (TPA)-induced differentiation of a megakaryocyte precursor cell line into megakaryocytes. Thus, high levels of Runx1 tyrosyl phosphorylation correlated with an undifferentiated state, and low levels correlated with differentiation. Purified c-Src was confirmed to function as a Runxl tyrosyl kinase, and inhibitors of c-Src kinase, including Dasatinib, which is known to promote megakaryocyte differentiation (Mazharian et al. 2011), reduced Runxl tyrosyl phosphorylation. Furthermore, c-Src inhibitors increased the number, size, ploidy, and percentage of phenotypic megakaryocytes differentiated from fetal liver cells, and loss of Runx 1 blocked this effect.

Whereas SFKs appear to be major Runx1 kinases in hematopoietic cells, the investigators also provide evidence that Shp2 is an important Runxl phosphatase. In addition to copurifying with Runx1, Shp2 produced in reticulocyte lysates bound directly to bacterially produced GST-Runx1, suggestive of a direct interaction. Furthermore, Shp2 depletion (via shRNA) in megakaryocytes or Shp2 deletion in thymocytes resulted in enhanced Runx1 tyrosyl phosphorylation. There also were significant similarities between the effects of Shp2 deletion on megakaryocyte and thymocyte development. Notably, while most studies on Shp2 have focused on its effects immediately downstream from receptor tyrosyl kinases and cytokine receptors (Neel et al. 2009), Runxl is the latest member of a small set of proposed nuclear substrates for Shp2, which include Hox proteins (Huang et al. 2006) and the tumor suppressor gene Parafibromin (Takahashi et al. 2011).

Having mapped the phosphorylation sites, the investigators were able to generate important reagents for testing the effect of tyrosyl phosphorylation on Runxl activity. A Runx1 protein containing phenylalanine substitutions at five of the six phosphorylated tyrosines reduced Runx1 tyrosyl phosphorylation to almost background levels. They examined the activity of this nonphosphorylatable Runx1 $\left(\operatorname{Runx}^{5 \mathrm{~F}}\right)$ and a constitutive phosphorylation mimic with five aspartic acid substitutions (Runx $1^{5 \mathrm{D}}$ ) on the development of two blood cell lineages highly dependent on Runx1 activity, megakaryocytes, and $\mathrm{CD} 8^{+} \mathrm{T}$ lymphocytes. When introduced into wild-type fetal liver cells, the Runx $1^{5 \mathrm{D}}$ phosphomimetic construct inhibited megakaryocyte polyploidization and the expression of megakaryocytic cell surface differentiation markers, while Runx $1^{5 \mathrm{~F}}$ had the opposite effect. Transplantation of adult bone marrow cells into which Runxl and its mutants were retrovirally transduced resulted in highly impaired engraftment, most likely due to the propensity of overexpressed Runx 1 to drive HSCs into quiescence (Challen and Goodell 2010). The Runx $1^{5 \mathrm{D}}$ phosphomimetic protein slightly ameliorated this engraftment defect, while the nonphosphorylatable Runx $1^{5 \mathrm{~F}}$ exacerbated it, again suggesting that Runx1 tyrosyl phosphorylation has a supportive, or at least permissive, role in promoting cell proliferation.

Pan-hematopoietic loss of Runxl inhibits T-cell differentiation within the double-negative stages (Ichikawa et al. 2004; Growney et al. 2005). Introduction of the nonphosphorylatable Runx $1^{5 \mathrm{~F}}$ mutant into Runx1-deficient bone marrow cells robustly rescued T-cell differentiation up through the $\mathrm{CD}^{+}$stage-even better than did wild-type Runx1-while the phosphomimetic Runx $1^{5 \mathrm{D}}$ protein completely failed to rescue the formation of $\mathrm{CD}^{+}$ T cells. Furthermore, overexpression of Runx $1^{5 \mathrm{D}}$ in wildtype bone marrow cells derepressed $C d 4$ expression in $\mathrm{CD}^{+}$cells, resulting in the appearance of abnormal, $\mathrm{CD}^{+} \mathrm{CD}^{+}$cells in the periphery, which are never seen in normal animals. The appearance of $\mathrm{CD} 4^{+} \mathrm{CD} 8^{+}$cells was presumably caused by dominant inhibition of wildtype Runx1 and Runx3, which normally silence Cd4 expression in mature $\mathrm{CD}^{+}$cells (Taniuchi et al. 2002; Woolf et al. 2003). Thus, tyrosyl phosphorylation inhibited the ability of Runxl to drive differentiation of both T cells and megakaryocytes and silence $C d 4$ expression.

Finally, the investigators examined the effect of tyrosyl phosphorylation on the interaction of Runxl with several of its associated proteins, including several transcription factors with which it partners during megakaryocyte differentiation (Gata1, Fli1, and CBF $\beta$ ), and with components of the chromatin remodeling SWI/SNF complex. TPA-induced differentiation of a megakaryocyte progenitor line, which correlated with loss of tyrosyl phosphorylation, caused the SWI/SNF proteins Brgl and Snf5 to dissociate from Runx1. On the other hand, treatment with the global tyrosyl phosphatase inhibitor sodium vanadate, which also led to increased Runx1 tyrosyl phos- 
phorylation, favored its interaction with Brg1 and Snf5 and decreased the interaction with Gata1, Fli1, and CBF $\beta$.

The results lead to a model in which Runxl functions like a single-pole double-throw switch that is regulated by tyrosyl phosphorylation (Fig. 2). When Runx1 is phosphorylated on tyrosines in response to growth signals by activated SFKs, it associates preferentially with the chromatin remodelers Brg1 and Snf5, and this correlates with an undifferentiated progenitor state. Since overexpression of the tyrosyl phosphomimetic protein caused effects similar to those induced by Runxl deficiency, it is not clear whether tyrosyl phosphorylated Runxl actively contributes to maintaining the progenitor state or whether Runxl is inactivated by tyrosyl phosphorylation. Loss of phosphorylation causes the interaction with the SWI/SNF proteins to be disfavored, and preferential association with other transcription factor partners drives differentiation.

These new findings raise many interesting biochemical and biological questions. Do seryl/threonyl and tyrosyl phosphorylation directly affect the association of transcriptional partners and epigenetic coregulators to the Runx1 inhibitory regions, or do they induce a conformational change in Runx1 that exposes other autoinhibited domains with which these proteins can now interact? Fine mapping of the binding sites for the interacting proteins on Runx1 might help sort this out. Unfortunately, fulllength Runxl is notoriously difficult to purify; thus, the types of biophysical studies used-for example, to study how the autoinhibited conformation of Ets-1 is relieved by phosphorylation-will be hard to conduct (Pufall et al. 2005). If tyrosyl phosphorylation directly promotes Runx1 binding to other regulatory proteins, such interactions (unlike Stat homodimers and heterodimers) do not involve phosphotyrosyl- binding modules such as $\mathrm{SH} 2$ or PTB domains. Notably, the Runx $1^{5 \mathrm{~F}}$ mutant also was
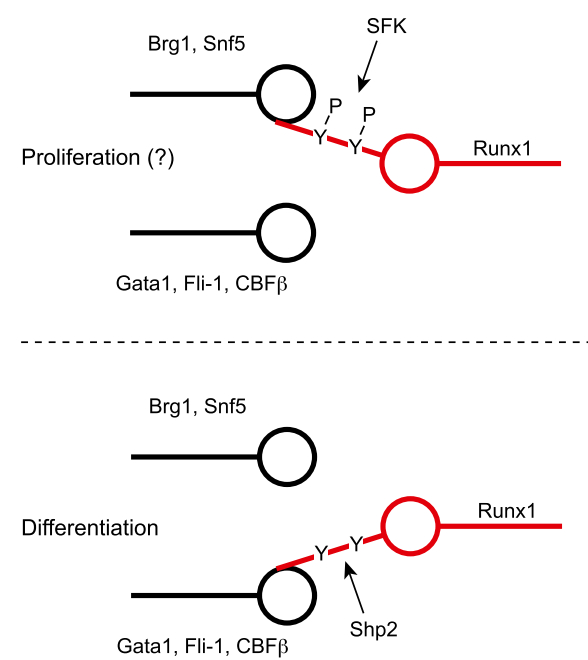

Figure 2. Runxl preferentially interacts with the SWI/SNF Brg1 and Snf5 subunits when tyrosyl phosphorylated by SFKs and interacts with the transcriptional coregulators Gatal, Fli-1, and $\mathrm{CBF} \beta$ when unphosphorylated by Shp2. Whether or not tyrosyl phosphorylated Runxl actively promotes proliferation is unknown. consistently expressed at lower levels than wild-type Runx1 or Runx $1^{5 \mathrm{D}}$, raising the possibility that tyrosyl phosphorylation might also affect Runxl stability.

Another important and related question concerns the low stoichiometry $(<5 \%)$ of Runxl tyrosyl phosphorylation observed by Huang et al. (2012). At first glance, it is difficult to understand how an inhibitory modification that occurs on such a small fraction of cellular Runx1 can have the proposed biological effects. As the investigators suggest, a particular pool of Runxl-e.g., that bound to chromatin, or perhaps Runx1 within a specific coreceptor complex-might be much more heavily tyrosyl phosphorylated. It will be important to test and resolve these possibilities.

The precise mechanisms of Runxl tyrosyl phosphorylation and dephosphorylation also merit clarification. Although SFKs are clearly required for Runx1 tyrosyl phosphorylation, it is unclear whether they directly phosphorylate all of the Runx1 phosphorylation sites or instead prime certain sites to recruit other tyrosine kinases. Indeed, the behavior of the tyrosine>phenylalanine mutants studied by Huang et al. (2012) raise the possibility that phosphorylation of some sites might be required for phosphorylation of others. Also unclear is where Runx1 tyrosyl phosphorylation/dephosphorylation takes place. In this regard, the investigators note that Src and Shp2 are localized in the cytoplasm and nucleus of cells in which Runx1 is tyrosyl phosphorylated. It is unclear whether the location of these signaling molecules is developmentally regulated during hematopoiesis and, if so, which signaling pathways control localization. How Shp2 binds to Runx1 also remains to be elucidated. Most Shp2interacting proteins bind either its $\mathrm{SH} 2$ domains or its C-terminal tyrosyl phosphorylation sites (Neel et al. 2009). Because bacterial GST-Runx1 binds to Shp2 produced by in vitro translation, the interaction cannot be mediated via the Shp2 SH2 domains. Although Shp2 could be tyrosyl phosphorylated in reticulocyte lysates, there also is no obvious phosphotyrosyl-binding motif in Runx1. The only other apparent binding motif in Shp2 is a conserved proline-rich motif with as yet unknown function within its C-terminal domain, but again, Runxl is not known to have a binding site for proline-rich proteins.

Tyrosyl phosphorylation of Runxl is correlated with a proliferative progenitor-like state, but does tyrosyl phosphorylated Runx1 actively promote proliferation? Runx1 is known to regulate both quiescence and $\mathrm{G}_{1}$-to-S cell cycle progression (Strom et al. 2000; Bernardin and Friedman 2002; Challen and Goodell 2010; Cai et al. 2011). A seryl/ threonyl phosphorylated Runxl mimic promotes proliferation of a cell line better than wild-type Runx1 (F Zhang et al. 2008), so the effects on maintaining a proliferative progenitor state may be similar for seryl/threonyl and tyrosyl phosphorylation. But how, then, are seryl/threonyl and tyrosyl phosphorylation coordinated during differentiation, especially as they seem to have opposing effects? Seryl/threonyl phosphorylation appears to be necessary for Runx1 to drive T-cell differentiation and Cd4 silencing (Yoshimi et al. 2012), whereas Huang et al. (2012) found 
that tyrosyl phosphorylation blocks this activity. Interestingly, a major role of Shp2 is to promote full activation of the RAS/ERK pathway (Neel et al. 2009). As ERK is also a major Runx1 kinase (Tanaka et al. 1996), Shp2 might coordinately regulate seryl/threonyl (indirectly) and tyrosyl (directly) phosphorylation of Runxl and thereby play a particularly important role in Runxl regulation.

Finally, and perhaps most interestingly, does dysregulation of Runx1 phosphorylation contribute to hematological malignancies associated with mutations in which SFK pathways are activated or with somatic mutations in PTPN11? PTPN11 mutations that disable SHP2 autoinhibition and result in "activated mutants" are a major cause of the childhood myeloproliferative disease juvenile myelomonocytic leukemia (JMML) and contribute to acute leukemias (Chan and Feng 2007; Chan et al. 2008; Liu and Qu 2011). The work of Huang et al. (2012) suggests that PTPN11 mutant JMML cells should primarily contain RUNX1 lacking tyrosyl phosphorylation. Runx1 gain-of-function mutations as a result of retroviral integration will cause myeloid leukemia and T-cell lymphomas in mice (Cameron and Neil 2004), and although RUNX1 gain-of-function mutations in AML have not, to our knowledge, been identified in human patients, there are multiple reports that a region surrounding the RUNX1 locus is amplified in a subset of B-ALL (Perez-Vera et al. 2008). The consequences of JMML-associated PTPN11 mutants on the T-cell lineage (Mohi et al. 2005; Chan et al. 2009) are intriguingly similar to those of the Runx $1^{5 \mathrm{~F}}$ mutant seen in the present study. However, previous work has shown that the $\mathrm{SH} 2$ domains, the C-terminal tyrosyl phosphorylation sites, and the scaffolding adapter Gab2 (Mohi et al. 2005), in addition to tyrosyl phosphatase activity (Mohi et al. 2005; Schubbert et al. 2005), are required for mutant PTPN11-induced myeloproliferation, at least in mice, and as discussed above, it is hard to see how any of these domains/intermediates would be required for SHP2-mediated RUNX1 dephosphorylation. Furthermore, several other mutations that cause JMML KRAS and NRAS gain-of-function alleles or homozygous NF1 loss of function (Schubbert et al. 2007; Liu et al. 2012) are believed to lie downstream from SHP2 in receptor tyrosine kinase and cytokine signaling, and it is unclear how/whether they too would converge to dephosphorylate RUNX1. Nevertheless, the unexpected nexus between SFKs, RUNX1, and SHP2 represents an arena for future investigations into normal and abnormal hematopoiesis.

\section{Acknowledgments}

B.N. is supported by R37CA49132 and is a Canada Research Chair, Tier 1. N.A.S. is supported by R01HL091724, R01CA149976, and the Abramson Family Cancer Research Institute.

\section{References}

Aikawa Y, Nguyen LA, Isono K, Takakura N, Tagata Y, Schmitz ML, Koseki H, Kitabayashi I. 2006. Roles of HIPK1 and HIPK2 in AML1- and p300-dependent transcription, hematopoiesis and blood vessel formation. EMBO I 25: 3955-3965.
Bakshi R, Hassan MQ, Pratap J, Lian JB, Montecino MA, van Wijnen AJ, Stein JL, Imbalzano AN, Stein GS. 2010. The human SWI/SNF complex associates with RUNX1 to control transcription of hematopoietic target genes. I Cell Physiol 225: 569-576.

Bernardin F, Friedman AD. 2002. AML1 stimulates G1 to S progression via its transactivation domain. Oncogene 21: 3247-3252.

Biggs JR, Peterson LF, Zhang Y, Kraft AS, Zhang DE. 2006. AML1/RUNX1 phosphorylation by cyclin-dependent kinases regulates the degradation of AML1/RUNX1 by the anaphasepromoting complex. Mol Cell Biol 26: 7420-7429.

Cai X, Gaudet JJ, Mangan JK, Chen MJ, De Obaldia ME, Oo Z, Ernst P, Speck NA. 2011. Runx1 loss minimally impacts long-term hematopoietic stem cells. PLOS ONE 6: e28430. doi: 10.1371 /journal.pone.0028430.

Cameron ER, Neil JC. 2004. The Runx genes: Lineage-specific oncogenes and tumor suppressors. Oncogene 23: 4308-4314.

Canon J, Banerjee U. 2003. In vivo analysis of a developmental circuit for direct transcriptional activation and repression in the same cell by a Runx protein. Genes Dev 17: 838843.

Challen GA, Goodell MA. 2010. Runx1 isoforms show differential expression patterns during hematopoietic development but have similar functional effects in adult hematopoietic stem cells. Exp Hematol 38: 403-416.

Chan RJ, Feng GS. 2007. PTPN11 is the first identified protooncogene that encodes a tyrosine phosphatase. Blood 109: 862-867.

Chan G, Kalaitzidis D, Neel BG. 2008. The tyrosine phosphatase Shp2 (PTPN11) in cancer. Cancer Metastasis Rev 27: 179192.

Chan G, Kalaitzidis D, Usenko T, Kutok JL, Yang W, Mohi MG, Neel BG. 2009. Leukemogenic Ptpn11 causes fatal myeloproliferative disorder via cell-autonomous effects on multiple stages of hematopoiesis. Blood 113: 4414-4424.

Collins A, Littman DR, Taniuchi I. 2009. RUNX proteins in transcription factor networks that regulate T-cell lineage choice. Nat Rev Immunol 9: 106-115.

Djuretic IM, Cruz-Guilloty F, Rao A. 2009. Regulation of gene expression in peripheral $\mathrm{T}$ cells by Runx transcription factors. Adv Immunol 104: 1-23.

Egawa T, Tillman RE, Naoe Y, Taniuchi I, Littman DR. 2007. The role of the Runx transcription factors in thymocyte differentiation and in homeostasis of naive T cells. J Exp Med 204: 1945-1957.

Elagib KE, Racke FK, Mogass M, Khetawat R, Delehanty LL, Goldfarb AN. 2003. RUNX1 and GATA-1 coexpression and cooperation in megakaryocyte differentiation. Blood 101: 4333-4341.

Flores G, Duan H, Yan H, Nagaraj R, Fu W, Zou Y, Noll M, Banerjee U. 2000. Combinatorial signaling in the specification of unique cell fates. Cell 103: 75-85.

Grossmann V, Kern W, Harbich S, Alpermann T, Jeromin S, Schnittger S, Haferlach C, Haferlach T, Kohlmann A. 2011a. Prognostic relevance of RUNX1 mutations in T-cell acute lymphoblastic leukemia. Haematologica 96: 1874-1877.

Grossmann V, Kohlmann A, Zenger M, Schindela S, Eder C, Weissmann S, Schnittger S, Kern W, Muller MC, Hochhaus A, et al. 2011b. A deep-sequencing study of chronic myeloid leukemia patients in blast crisis (BC-CML) detects mutations in $76.9 \%$ of cases. Leukemia 25 : 557-560.

Growney JD, Shigematsu H, Li Z, Lee BH, Adelsperger J, Rowan R, Curley DP, Kutok JL, Akashi K, Williams IR, et al. 2005. Loss of Runx1 perturbs adult hematopoiesis and is associated with a myeloproliferative phenotype. Blood 106: 494-504. 
Gu T-L, Goetz TL, Graves BJ, Speck NA. 2000. Autoinhibition and partner proteins, $\mathrm{CBF} \beta$ and Ets-1, modulate DNA binding by CBF 2 2(AML1). Mol Cell Biol 20: 91-103.

Guo H, Friedman AD. 2011. Phosphorylation of RUNX1 by cyclin-dependent kinase reduces direct interaction with HDAC1 and HDAC3. J Biol Chem 286: 208-215.

Hernandez-Munain C, Krangel MS. 2002. Distinct roles for c-Myb and core binding factor/polyoma enhancer-binding protein 2 in the assembly and function of a multiprotein complex on the TCR $\delta$ enhancer in vivo. J Immunol 169: 4362-4369.

Huang W, Saberwal G, Horvath E, Zhu C, Lindsey S, Eklund EA. 2006. Leukemia-associated, constitutively active mutants of SHP2 protein tyrosine phosphatase inhibit NF1 transcriptional activation by the interferon consensus sequence binding protein. Mol Cell Biol 26: 6311-6332.

Huang H, Yu M, Akie TE, Moran TB, Woo AJ, Tu N, Waldon Z, Lin YY, Steen H, Cantor AB. 2009. Differentiation-dependent interactions between RUNX-1 and FLI-1 during megakaryocyte development. Mol Cell Biol 29: 4103-4115.

Huang G, Zhao X, Wang L, Elf S, Xu H, Sashida G, Zhang Y, Liu Y, Lee J, Menendez S, et al. 2011. The ability of MLL to bind RUNX1 and methylate $\mathrm{H} 3 \mathrm{~K} 4$ at PU.1 regulatory regions is impaired by MDS/AML-associated RUNX1/AML1 mutations. Blood 118: 6544-6552.

Huang J, Woo AJ, Waldon Z, Schindler Y, Moran TB, Zhu HH, Feng GS, Steen H, Cantor AB. 2012. A Src family kinaseShp2 axis controls RUNX1 activity in megakaryocyte and T-lymphocyte differentiation. Genes Dev (this issue). doi: 10.1101/gad.192054.112.

Ichikawa M, Asai T, Saito T, Yamamoto G, Seo S, Yamazaki I, Yamagata T, Mitani K, Chiba S, Ogawa S, et al. 2004. AML-1 is required for megakaryocytic maturation and lymphocytic differentiation, but not for maintenance of hematopoietic stem cells in adult hematopoiesis. Nat Med 10: 299-304.

Kanno T, Kanno Y, Chen L-F, Ogawa E, Kim W-Y, Ito Y. 1998. Intrinsic transcriptional activation-inhibition domains of the polyomavirus enhancer binding protein 2 /core binding factor $\alpha$ subunit revealed in the presence of the $\beta$ subunit. Mol Cell Biol 18: 2444-2454.

Kitabayashi I, Yokoyama A, Shimizu K, Ohki M. 1998. Interaction and functional cooperation of the leukemia-associated factors AML1 and p300 in myeloid cell differentiation. EMBO J 17: 2994-3004.

Levanon D, Goldstein RE, Bernstein Y, Tang H, Goldenberg D, Stifani S, Paroush Z, Groner Y. 1998. Transcriptional repression by AML1 and LEF-1 is mediated by the TLE/Groucho corepressors. Proc Natl Acad Sci 95: 11590-11595.

Liu X, Qu CK. 2011. Protein tyrosine phosphatase SHP-2 (PTPN11) in hematopoiesis and leukemogenesis. I Signal Transduct 2011: 195239. doi: 10.1155/2011/195239.

Liu X, Sabnis H, Bunting KD, Qu CK. 2012. Molecular targets for the treatment of juvenile myelomonocytic leukemia. Adv Hematol 2012: 308252. doi: 10.1155/2012/308252.

Lorsbach RB, Moore J, Ang SO, Sun W, Lenny N, Downing JR. 2004. Role of Runx1 in adult hematopoiesis: Analysis of Runx1-IRES-GFP knock-in mice reveals differential lineage expression. Blood 103: 2522-2529.

Mangan JK, Speck NA. 2011. RUNX1 mutations in clonal myeloid disorders: From conventional cytogenetics to next generation sequencing, a story 40 years in the making. Crit Rev Oncog 16: 77-91.

Mazharian A, Ghevaert C, Zhang L, Massberg S, Watson SP. 2011. Dasatinib enhances megakaryocyte differentiation but inhibits platelet formation. Blood 117: 5198-5206.

Mohi MG, Williams IR, Dearolf CR, Chan G, Kutok JL, Cohen S, Morgan K, Boulton C, Shigematsu H, Keilhack H, et al.
2005. Prognostic, therapeutic, and mechanistic implications of a mouse model of leukemia evoked by Shp2 (PTPN11) mutations. Cancer Cell 7: 179-191.

Mukai K, Benbarak M, Tachibana M, Nishida K, Karasuyama H, Taniuchi I, Galli SJ. 2012. Critical role of P1-Runx1 in mouse basophil development. Blood doi: 10.1182/blood-2011-12-399113.

Neel BG, Chan G, Dhanji S. 2009. SH2 domain-containing proteintyrosine phosphatases. In Handbook of cell signaling, 2nd ed. (ed. RA Bradshaw, EA Dennis), pp. 771-810, Academic Press, Waltham, MA.

North TE, Gu T-L, Stacy T, Wang Q, Howard L, Binder M, Marín-Padilla M, Speck NA. 1999. Cbfa2 is required for the formation of intra-aortic hematopoietic clusters. Development 126: 2563-2575.

Perez-Vera P, Montero-Ruiz O, Frias S, Rivera-Luna R, Valladares A, Arenas D, Paredes-Aguilera R, Carnevale A. 2008. Multiple copies of RUNX1: Description of 14 new patients, follow-up, and a review of the literature. Cancer Genet Cytogenet 180: 129-134.

Pufall MA, Lee GM, Nelson ML, Kang HS, Velyvis A, Kay LE, McIntosh LP, Graves BJ. 2005. Variable control of Ets-1 DNA binding by multiple phosphates in an unstructured region. Science 309: 142-145.

Schubbert S, Lieuw K, Rowe SL, Lee CM, Li X, Loh ML, Clapp DW, Shannon KM. 2005. Functional analysis of leukemiaassociated PTPN11 mutations in primary hematopoietic cells. Blood 106: 311-317.

Schubbert S, Shannon K, Bollag G. 2007. Hyperactive Ras in developmental disorders and cancer. Natl Rev 7: 295-308.

Song W-J, Sullivan MG, Legare RD, Hutchings S, Tan X, Kufrin D, Ratajczak J, Resende IC, Haworth C, Hock R, et al. 1999. Haploinsufficiency of CBFA2 (AML1) causes familial thrombocytopenia with propensity to develop acute myelogenous leukamia (FPD/AML). Nat Genet 23: 166-175.

Strom DK, Nip J, Westendorf JJ, Linggi B, Lutterbach B, Downing JR, Lenny N, Hiebert SW. 2000. Expression of the AML-1 oncogene shortens the G(1) phase of the cell cycle. J Biol Chem 275: 3438-3445.

Takahashi A, Tsutsumi R, Kikuchi I, Obuse C, Saito Y, Seidi A, Karisch R, Fernandez M, Cho T, Ohnishi N, et al. 2011. SHP2 tyrosine phosphatase converts Parafibromin/Cdc73 from a tumor suppressor to an oncogenic driver. Mol Cell 43: 45-56.

Tanaka T, Kurokawa M, Ueki K, Tanaka K, Imai Y, Mitani K, Okazaki K, Sagata N, Yazaki Y, Shibata Y, et al. 1996. The extracellular signal-regulated kinase pathway phosphorylates AML1, an acute myeloid leukemia gene product, and potentially regulates its transactivation ability. Mol Cell Biol 16: 3967-3979.

Taniuchi I, Osato M, Egawa T, Sunshine JJ, Bae S-C, Komori T, Ito Y, Littman DR. 2002. Differential requirements for Runx proteins in $C D 4$ repression and epigenetic silencing during $\mathrm{T}$ lymphocyte development. Cell 111: 621-633.

Wang L, Huang G, Zhao X, Hatlen MA, Vu L, Liu F, Nimer SD. 2009. Post-translational modifications of Runxl regulate its activity in the cell. Blood Cells Mol Dis 43: 30-34.

Wong WF, Kohu K, Chiba T, Sato T, Satake M. 2011. Interplay of transcription factors in T-cell differentiation and function: The role of Runx. Immunology 132: 157-164.

Woolf E, Xiao C, Fainaru O, Lotem J, Rosen D, Negreanu V, Bernstein Y, Goldenberg D, Brenner O, Berke G, et al. 2003. Runx3 and Runx1 are required for CD8 T cell development during thymopoiesis. Proc Natl Acad Sci 100: 7731-7736.

Yoshida H, Kitabayashi I. 2008. Chromatin regulation by AML1 complex. Int J Hematol 87: 19-24.

Yoshimi M, Goyama S, Kawazu M, Nakagawa M, Ichikawa M, Imai Y, Kumano K, Asai T, Mulloy JC, Kraft AS, et al. 2012. 
Neel and Speck

Multiple phosphorylation sites are important for RUNX1 activity in early hematopoiesis and T-cell differentiation. Eur I Immunol 42: 1044-1050.

Yu M, Mazor T, Huang H, Huang HT, Kathrein KL, Woo AJ, Chouinard CR, Labadorf A, Akie TE, Moran TB, et al. 2012. Direct recruitment of polycomb repressive complex 1 to chromatin by core binding transcription factors. Mol Cell 45: 330-343.

Zelent A, Greaves M, Enver T. 2004. Role of the TEL-AML1 fusion gene in the molecular pathogenesis of childhood acute lymphoblastic leukaemia. Oncogene 23: 4275-4283.

Zhang F, Meng G, Strober W. 2008. Interactions among the transcription factors Runx1, ROR $\gamma \mathrm{t}$ and Foxp3 regulate the differentiation of interleukin 17-producing $\mathrm{T}$ cells. Nat Immunol 9: 1297-1306.

Zhang L, Fried FB, Guo H, Friedman AD. 2008. Cyclin-dependent kinase phosphorylation of RUNX1/AML1 on 3 sites increases transactivation potency and stimulates cell proliferation. Blood 111: 1193-1200.

Zhang J, Ding L, Holmfeldt L, Wu G, Heatley SL, Payne-Turner D, Easton J, Chen X, Wang J, Rusch M, et al. 2012. The genetic basis of early T-cell precursor acute lymphoblastic leukaemia. Nature 481: 157-163. 


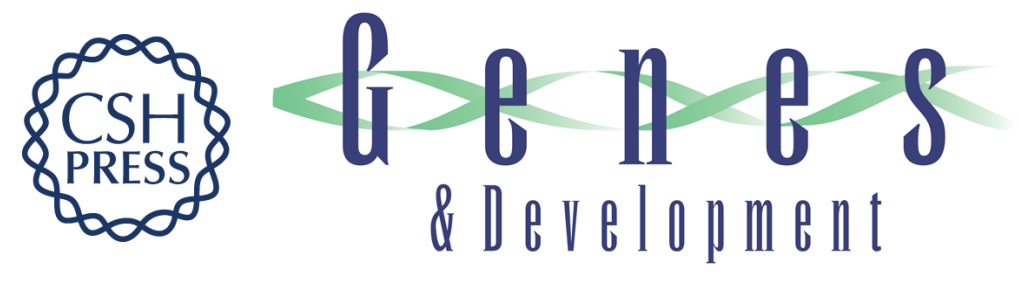

\title{
Tyrosyl phosphorylation toggles a Runx1 switch
}

\author{
Benjamin G. Neel and Nancy A. Speck
}

Genes Dev. 2012, 26:

Access the most recent version at doi:10.1101/gad.198051.112

\section{Related Content A Src family kinaseShp2 axis controls RUNX1 activity in megakaryocyte and T-lymphocyte differentiation Hui Huang, Andrew J. Woo, Zachary Waldon, et al. Genes Dev. July, 2012 26: 1587-1601}

References This article cites 55 articles, 26 of which can be accessed free at: http://genesdev.cshlp.org/content/26/14/1520.full.html\#ref-list-1

Articles cited in:

http://genesdev.cshlp.org/content/26/14/1520.full.html\#related-urls

\section{License}

Email Alerting

Service

Receive free email alerts when new articles cite this article - sign up in the box at the top right corner of the article or click here.

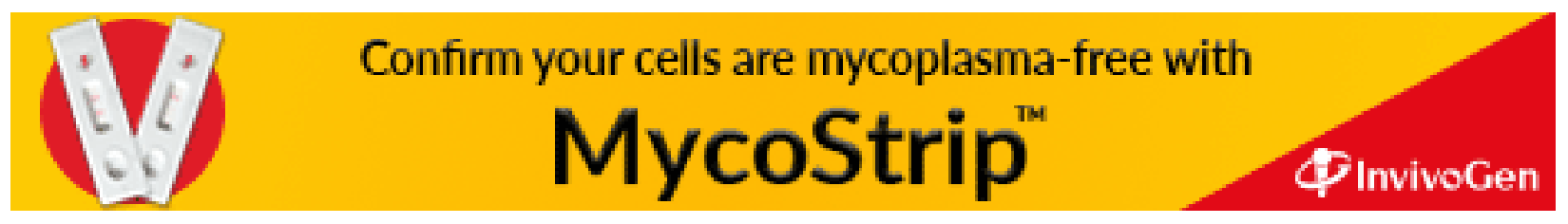

